\title{
Identifying Alternate Resources and Adjusting Expectations for Senior Design Projects During the COVID-19 Pandemic of 2020
}

\author{
JAY R. GoldBerg (1) \\ Department of Biomedical Engineering, Marquette University and the Medical College of Wisconsin, P.O. Box 1881, \\ Milwaukee, WI 53201-1881, USA
}

(Received 19 June 2020; accepted 23 July 2020; published online 13 August 2020)

\begin{abstract}
In March 2020, the COVID-19 pandemic required capstone design course instructors to transition to online learning. Student project teams were denied access to resources needed to construct and test prototypes scheduled to be delivered to project sponsors and clients at the end of the semester. Face-to-face collaboration was replaced with virtual team meetings. At Marquette University, efforts to identify (1) barriers to completing projects, (2) potential alternate prototyping resources, (3) adjustments to expectations of teams, and (4) changes to course deliverable requirements were completed. The results of these activities, the thought process used to guide students through the search for alternate resources, and final outcomes of student projects along with a discussion of what was learned from this experience are presented.
\end{abstract}

Keywords-Project resources, Risk management, Contingency planning, Virtual teams, Online teaching.

\section{CHALLENGE}

Senior biomedical engineering capstone design courses provide students with a team-based project experience in solving an open-ended, real-world medical problem. The focus of these courses is typically on the project, which requires student teams to design, construct, and test prototypes of their final designs and deliver them to sponsors or clients. Much of the learning that occurs in capstone design courses takes place outside of the classroom through hands-on experiences, which are forms of active and student-

Address correspondence to Jay R. Goldberg, Department of Biomedical Engineering, Marquette University and the Medical College of Wisconsin, P.O. Box 1881, Milwaukee, WI 53201-1881, USA. Electronic mail: jay.goldberg@mu.edu centered learning. ${ }^{1}$ For most projects, students need access to maker spaces, tools, test equipment, test space, purchased parts, and components to complete their projects.

During the second half of the spring 2020 semester, the COVID-19 pandemic presented unique challenges to capstone design students as they tried to complete construction and testing of their prototypes. At Marquette University, most students remained at home after spring break, and classes transitioned to online instruction. Project teams had been collaborating in person for 7 months, allowing them to build trust and effective channels of communication. Students scattered across the country as well as those that returned to campus apartments were suddenly denied access to the Discovery Learning Laboratory (DLL), the main maker space for engineering students at Marquette University, and equipment needed for verification testing. Some had prototype parts stored in a locker in the DLL, making it difficult to build and test prototypes by the end of the semester. Some lost access to needed design and simulation software.

\section{NOVEL INITIATIVE}

At the start of the shutdown, the immediate goals were to (1) determine how to deliver remaining course lectures, (2) assess the level of progress student teams would be able to make towards completing their projects, (3) investigate alternate resources that might be available to students to help them complete their prototypes, (4) determine how to adjust expectations 
of teams and their project scope, and (5) determine changes in course deliverable requirements and grading for teams that could not complete their prototypes. The literature provided guidance for delivering lectures (\#1 above), but no references were found to help accomplish the remaining goals during a pandemic. The approach presented here had not been described in the literature and out of necessity was developed during the first week of the shutdown. The lack of guidance from the literature required a novel approach to identify alternate resources, and adjustments to expectations, course deliverable requirements, and grading.

Remaining course lectures were delivered through a combination of live (synchronous) Microsoft (MS) Teams and Zoom lectures, and asynchronous voiceover Power Point presentations. The Center for Teaching and Learning (CTL) at Marquette University provided training and support to assist faculty in effective online teaching using these and other tools. This approach was not novel and online teaching of capstone courses had been previously described in the literature. ${ }^{3,5}$

Students began meeting with their teammates and faculty project advisors via MS Teams. The course instructor met with each project team (typically consisting of five students) biweekly using MS Teams to discuss and assess the progress each could make towards completing its final prototype, and to discuss potential alternate resources that could help the team. This process began with determining the status of each project, what would be needed to complete the project, and what barriers and lack of resources prevented the team from doing so. Once the barriers were identified, alternate resources were brainstormed to see which might be accessible and feasible to use to overcome these barriers. After discussions between the course instructor and faculty and staff, some needed resources were made available to students:

- Teams with members who remained on campus or lived within driving distance to campus, with prototype parts stored in the DLL, were allowed to retrieve the parts while following appropriate social distancing practices.

- Licenses for simulation and modeling software (such as Solid Works) were made available for use of the software on students' laptop computers to continue design work remotely.

- Students were allowed to submit their CAD drawings to the DLL for 3D printing of prototype parts. After printing, parts were safely transferred by shipping them to students at their homes or campus addresses.
- Students who returned to campus were allowed to borrow tools such as soldering guns, and test equipment such as multimeters and function generators for use in their apartments.

Students were encouraged to do what they could to make as much progress as possible and not stop work due to the lack of normally available resources. They were asked to be creative and consider alternate local resources that might be available to them during the lockdown but would not require violating social distancing practices or jeopardize their health. These included:

- Maker spaces: home workshop, apartment, industry sponsor's machine shop, and community maker spaces (only if social distancing was possible).

- Test equipment: items they might have had at home (timers, scales, tape measures, multimeters, etc.) that could have been used for measurements and tests to support design verification activities.

- Prototype parts: materials, supplies, and parts that were locked in the DLL and inaccessible. If project budgets allowed, students could have ordered duplicates and have them shipped to their homes.

- Tools for prototype construction: items a team might have needed to complete their prototypes. If project budgets allowed, inexpensive models of soldering irons, multimeters, or other tools could have been ordered online for delivery to one of their member's home.

- Design software/3D printing: CAD software needed to design prototype parts. Students were able to obtain licenses to use CAD software on their laptop computers. They were also able to send files to commercial 3D printing services to have parts made. Some students had their own 3D printers and could print needed parts while at home.

After reviewing these local alternate resources, the course instructor and faculty project advisors determined if teams would be able to complete their projects, and if a change in project scope was justified. Figure 1 documents the thought process that was used to help students determine if they had the resources needed to complete their projects as originally planned and determine if changes to the scope of the projects were needed. ${ }^{2}$

For teams that were truly unable to complete their prototypes, lack of access to the necessary resources was considered when assigning a grade for the course, and no penalty was assessed. Grading was as flexible and accommodating as possible and was completed using a rubric specific to each spring semester course 


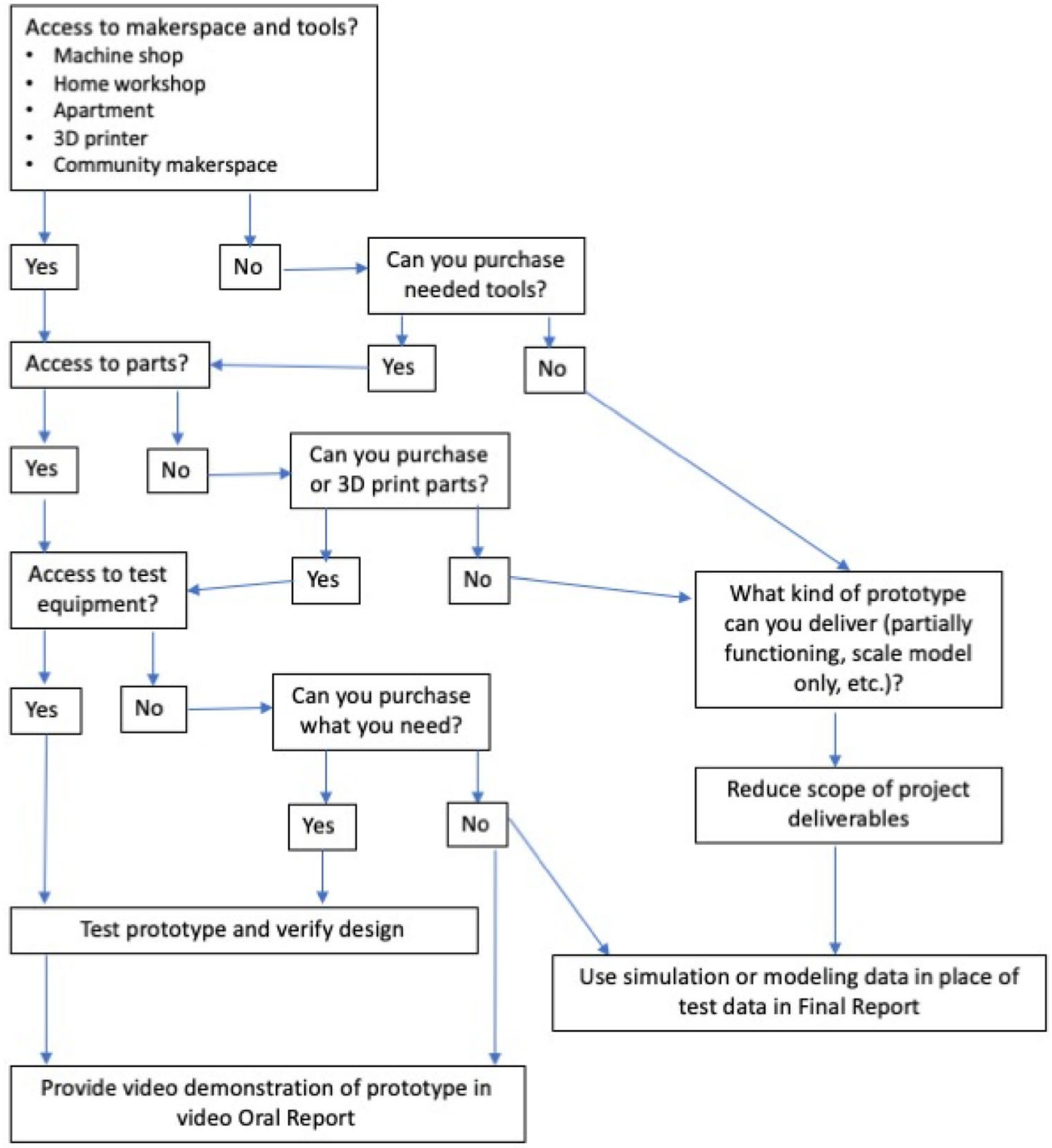

FIGURE 1. Thought process used to help students determine if they had the resources needed to complete their projects as originally planned and determine if changes to the scope of the projects were needed.

deliverable (Experimental Verification Document, Final Report, Oral Report, and Prototype). Weights for each requirement listed in these rubrics were established before the start of the semester. However, for those requirements that a team was not able to complete, the weight was adjusted to zero to avoid penalizing teams. The team did not receive full credit for these; the requirements were simply not included in the grading, giving greater weight to those requirements that the team was able to complete. For example, Table 1 shows the main sections of the rubric for the Experimental Verification Document, corresponding requirements, and a description of what would receive the highest score.

The section on Description of Experiments could be completed by all teams, regardless of the ability to conduct tests. Thus, the $20 \%$ weight was not adjusted for teams that were unable to complete their prototypes or testing. However, if no prototype existed, then no laboratory testing was possible, and the section on Results and Analysis of Experiments could not be completed unless the team performed a computer analysis or simulation to model or predict experimental results. If not, then the weighting was adjusted to $0 \%$. Finally, if testing (in the laboratory or via computer simulation) was not possible, then the performance claims requirement in the Conclusions section would not apply, but the requirement for recommended design changes might have been possible for teams that performed a careful analysis of their design prior to testing. In this case, the $35 \%$ weight for this section was applied to the requirement for recommended design changes. 
TABLE 1. Summary of requirements in rubric used to grade the experimental verification document deliverable.

\begin{tabular}{|c|c|}
\hline \multicolumn{2}{|c|}{ Description of experiments (20\%) } \\
\hline Requirement \#1 & $\begin{array}{l}\text { Clear, thorough, justifiable, and reasonable experimental plan including } \\
\text { a rationale for each test and detailed test procedures }\end{array}$ \\
\hline High score & $\begin{array}{l}\text { Each experiment has a clear rationale; experimental plan includes sample } \\
\text { sizes and number of replications, detailed description of test procedures, } \\
\text { and choice of data analysis methods }\end{array}$ \\
\hline Requirement \#2 & Appropriate apparatus \\
\hline High score & Appropriate methodology and calibrated apparatus (if available) used for experiment \\
\hline Requirement \#3 & Appropriate sample sizes \\
\hline High score & $\begin{array}{l}\text { Appropriate sample size used; analysis included to support choice of } \\
\text { sample size. Suitable justification given for not using ideal sample size. }\end{array}$ \\
\hline \multicolumn{2}{|c|}{ Results and analysis of experiments (35\%) } \\
\hline Requirement \#1 & Summary and analysis of data \\
\hline High score & $\begin{array}{l}\text { Summary and analysis of data presented; calculations correctly performed, } \\
\text { and deviations are explained }\end{array}$ \\
\hline Requirement \#2 & Appropriate data analysis methods \\
\hline High score & $\begin{array}{l}\text { Correct statistical method used to analyze data; analysis performed correctly; } \\
\text { statistically valid conclusions drawn. }\end{array}$ \\
\hline \multicolumn{2}{|r|}{ (2) } \\
\hline Requirement \#1 & Performance claims based on test results \\
\hline High score & $\begin{array}{l}\text { Reader convinced that performance requirements and customer needs have been } \\
\text { met or suitable reasons have been given for not meeting these needs. }\end{array}$ \\
\hline Requirement \#2 & Recommendations for design changes to improve design \\
\hline High score & $\begin{array}{l}\text { Design recommendations supported by experimental results; reader convinced } \\
\text { that proposed design changes will improve design }\end{array}$ \\
\hline
\end{tabular}

Note that section on document structure, grammar, and spelling (10\%) has not been included in this table.

TABLE 2. Summary of accommodations and final status of course deliverables.

\begin{tabular}{|c|c|c|c|}
\hline Course deliverable & Final status & $\%$ of teams & ( $n=21$ teams) \\
\hline \multirow[t]{2}{*}{ Experimental verification document } & Able to generate test data & 67 & $(n=14)$ \\
\hline & Computer simulations or analytical modeling only & 33 & $(n=7)$ \\
\hline \multirow[t]{3}{*}{ Final prototype } & Completed functional prototypes & 48 & $(n=10)$ \\
\hline & Non-functional mockups & 43 & $(n=9)$ \\
\hline & Non-functional scale models & 9 & $(n=2)$ \\
\hline \multirow[t]{2}{*}{ Oral report } & Live, synchronous & 14 & $(n=3)$ \\
\hline & Asynchronous, voice-over Power Point presentations & 86 & $(n=18)$ \\
\hline
\end{tabular}

Students were informed of how the grading rubrics would be modified for each project. This reduced the stress of teams fearful of a poor grade due to circumstances beyond their control and kept them motivated to complete as much of their projects as possible. Each project was different, at different stages of design, and was considered separately when assigning grades and determining if a change to the scope of the project and course deliverables were appropriate. The following accommodations were made when grading design verification and validation results, final prototypes, and oral reports, and are summarized along with the final status of course deliverables in Table 2.

\section{Design Verification}

Simulations and mathematical modeling data (FMEA, circuit analyses, etc.) were accepted if actual test data was not available due to inability to test the final prototype. Fourteen $(67 \%)$ teams were able to generate test data for verification testing, and seven $(33 \%)$ teams were only able to submit results of computer simulations or analytical modeling.

\section{Design Validation}

For those teams that were able to complete prototypes and verification testing of assistive devices, access to clients with disabilities was not possible due to the compromised medical condition of their clients. Faceto-face meetings with industry and faculty project 
sponsors to obtain feedback on device designs were not possible due to stay-at-home orders. Some teams were able to ship their prototypes to industry sponsors and obtain feedback via MS Teams or Zoom meetings. The design validation requirement was waived for most teams.

\section{Final Prototypes}

Scale models, detailed CAD drawings and/or renderings, and partially functioning or nonfunctioning prototypes (mockups) were accepted if functional prototypes could not be completed. Ten of the 21 teams $(48 \%)$ were able to complete their prototypes without additional resources due to planning ahead, earlier prototype construction, ability to write code remotely, storage of prototype parts in their campus apartments, and other factors. Nine teams (43\%) submitted a non-functional prototype (mockup) and two teams $(9 \%)$ submitted non-functional scale models.

\section{Oral Reports}

To conserve bandwidth for many of our students living at home, students were given the choice of presenting live via MS Teams or asynchronously via voiceover Power Point presentations. Three teams requested live oral reports and 18 teams chose to submit voiceover Power Point presentations.

If teams were unable to construct and test their prototypes, they were asked to include a section in their final written and oral reports that addressed the potential alternate resources that they identified and investigated, and why these resources were not enough to allow them to complete their prototypes.

All teams were required to submit detailed assembly instructions, lists of verification test procedures, and other information that would allow a future team (capstone design team or industry sponsor team) to reconstruct the project and continue work that the current team was unable to complete. They were also required to submit a project legacy that discussed what worked well and what did not, along with recommendations to a future team regarding potential design improvements that the current team was unable to implement and test.

\section{REFLECTION}

The COVID-19 pandemic and the resulting stay-athome orders provided an ongoing real-time, real-world lesson in contingency planning and finding alternate resources to complete projects. This situation was used as a learning opportunity (without causing additional stress to students). Industry sponsors of design projects were very understanding as to why some of them did not receive completed prototypes for projects that they funded. Most of them were dealing with similar issues including working at home, closed machine shops, and other limitations. Two of the six industry sponsored projects were software-based and did not require the same resources as did physical prototypes and were thus more easily completed remotely.

At the beginning of transition to online learning, the instructor's priority was to help students complete as much of their projects as possible with a focus on meeting the course learning objectives so they could successfully complete the course and graduate on time. This course focused on student learning, not on delivering a fully functional prototype to an industry sponsor. When grading, evidence from written final reports that teams were able to (1) understand and implement the design and project management process, (2) justify their design choices, (3) explain what they would do to produce a functional design if they had the appropriate resources and time, (4) suggest and justify future design changes, and (5) get around barriers, served as an indicator that course learning objectives were met. If the lack of prototyping resources prevented completion and delivery of the final prototype, then the scope of an individual project was modified including the course deliverables (such as the final prototype) to accept what teams were able to deliver at the end of the semester with the alternate resources that they had access to. However, students were not allowed to "give up" and conclude that no further progress could be made on their projects due to the lack of resources. Based on the status of each team's final deliverables and the evidence from the written final reports discussed above, all teams met the learning outcomes of the course.

Although plans for upcoming semesters at Marquette University include in-class teaching, the use of hybrid models that include a mix of in-class, synchronous online, and asynchronous online components has been urged. Student access to on campus maker spaces will be limited so it will be important for teams to plan ahead and identify alternate resources for prototype construction and testing before a possible shift back to all online learning is announced depending on the severity of the pandemic. An online demonstration of how to construct non-functional mockups and prototypes using simple, readily accessible tools and materials, such as scissors, knives, and hot melt glue guns, and foam core, cardboard, wood, and glue, respectively, will be presented by a local 
industrial designer. This will reduce the risk of teams not being able to complete the mockup or prototype required at the end of the fall semester.

A review of potential alternate resources (available outside of the University) for each project will become a new required section of the current first semester Project Definition deliverable. This exercise in risk management and contingency planning may help teams complete their projects on time if University resources become inaccessible to them.

If teams are restricted to virtual meetings early in their projects, then steps can be taken to help team members build trust and establish effective patterns of communication, the two biggest challenges in managing virtual teams. ${ }^{6}$ Best practices in virtual team management have been published elsewhere and will be included in course lecture topics to prepare students to shift to all online meetings if necessary. ${ }^{4,7}$

In conclusion, it is easier to manage a project when things are going well. Project management skills are demonstrated when a team finds ways to get around barriers and solve problems. We don't want our students to give up when faced with challenges. There were project tasks that could be completed without a maker space (i.e., software development, developing test procedures for verification tests, generating improved designs, etc.). Finding creative, nonconventional ways to get around barriers and advance towards a goal was helpful to students in completing their capstone design projects and will also help them in their personal and professional lives.

\section{ACKNOWLEDGMENTS}

I would like to thank my capstone design course colleagues, Dr. Vikram Cariapa, and Dr. Chandana Tamma at Marquette University for their contributions towards establishing the process depicted in Fig. 1.

\section{COMPLIANCE WITH ETHICAL STANDARDS}

\section{CONFLICT OF INTEREST}

The authors declare that they have no conflicts of interest.

\section{AVAILABILITY OF DATA AND MATERIAL}

The author will make data available upon request.

\section{REFERENCES}

\footnotetext{
${ }^{1}$ Bonwell CC Eison JA. Active learning: creating excitement in the classroom. ASHEERIC Higher Education Report No. 1. Washington, DC: George Washington University; 1991.

${ }^{2}$ Goldberg JR. Finding alternate resources for completing senior design projects during the current COVID-19 pandemic. IEEE Pulse. 2020;11(3):38-40.

${ }^{3}$ Jamieson MV, et al. The University of Alberta chemical engineering capstone design course goes flipped!. In: Proceedings of the Canadian Engineering Education Association (CEEA) Conference, McMaster University, May 31June 3; 2013.

${ }^{4}$ Larson EW, Gray CF. Project management: the managerial process, 6th edn. New York: McGraw-Hill Education; 2014. pp. 401-402;

${ }^{5}$ Lewin DR, Barzilai A. Flipping the capstone process design course. In: 27th European Symposium on Computer Aided Process Engineering, 2017;40:2923-2928.

${ }^{6}$ Lipsinger R, DeRosa D. Virtual team success: a practical guide for working and leading from a distance. San Francisco, CA: Josse-Bass; 2010.

${ }^{7}$ Zaugg H, Davies RS. Communication skills to develop trusting relationships on global virtual engineering capstone teams. Eur J Eng Educ. 2013;38(2):228-233.
}

Publisher's Note Springer Nature remains neutral with regard to jurisdictional claims in published maps and institutional affiliations. 